\title{
Aspects de l'opinion et de la pratique du suffrage entre mai 1849 et décembre 1851 : le témoignage des élections partielles à l'Assemblée législative
}

\section{Raymond Huard}

\section{(2) OpenEdition}

\section{Journals}

Édition électronique

URL : http://journals.openedition.org/rh19/246

DOI : $10.4000 /$ rh 19.246

ISSN : $1777-5329$

Éditeur

La Société de 1848

Édition imprimée

Date de publication : 1 juin 2001

Pagination : $15-40$

ISSN : 1265-1354

\section{Référence électronique}

Raymond Huard, «Aspects de l'opinion et de la pratique du suffrage entre mai 1849 et décembre 1851 : le témoignage des élections partielles à l'Assemblée législative », Revue d'histoire du XIXe siècle [En ligne], 22 | 2001, mis en ligne le 28 novembre 2016, consulté le 10 décembre 2020. URL : http:// journals.openedition.org/rh19/246; DOI : https://doi.org/10.4000/rh19.246

Ce document a été généré automatiquement le 10 décembre 2020.

Tous droits réservés 


\title{
Aspects de l'opinion et de la pratique du suffrage entre mai 1849 et décembre $1851:$ le témoignage des élections partielles à l'Assemblée législative
}

\author{
Raymond Huard
}

1 La question était posée à la veille du coup d'État de décembre 1851 : quel serait le résultat des élections législatives de mai 1852, voire de l'élection présidentielle à venir? Bien qu'elle soit de l'ordre de la politique-fiction puisque le coup d'Etat est un fait accompli, il existe cependant un moyen de mieux connaitre l'évolution de l'opinion pendant les dernières années de la Seconde République, c'est d'étudier les nombreuses élections partielles à l'Assemblée législative qui ont eu lieu entre 1849 et 1851. Dans un travail, déjà ancien, portant sur les débuts de la Troisième République, Jacques Gouault avait montré l'intérêt de ce type de consultation pour une étude plus fine de l'opinion ${ }^{1}$ La Seconde République n'a pas suscité d'étude comparable. Si de nombreux travaux locaux - qui nous ont été fort utiles - mentionnent les élections partielles et en analysent parfois les résultats ${ }^{2}$, au plan national, on s'est intéressé surtout à une seule phase électorale, celle des mois de mars-avril 1850, parce qu'elle a suscité une vive réaction dans l'Assemblée législative et amené le vote de la loi du 31 mai 1850 limitant le suffrage universel ${ }^{3}$. Les votes militaires ont également attiré l'attention de Rémi Gossez ${ }^{4}$. L'étude globale des 64 scrutins qui ont eu lieu entre mai 1849 et décembre 1851 est pourtant beaucoup plus riche en enseignements 5 . Au-delà des informations neuves qu'elles peuvent donner sur les fluctuations de l'opinion entre 1849 et 1851, les élections partielles nous renseignent sur la modification quantitative et qualitative des forces politiques à l'Assemblée législative; elles révèlent à travers la dramatisation accrue des campagnes, l'évolution des comportements des électeurs de base et des forces politiques, royalistes, bonapartistes et démocrates; elles permettent de percevoir comment les démocrates et les républicains ont réagi concrètement - et non pas seulement en intentions - après le 
vote de la loi du 31 mai 1850. Elles sont l'occasion aussi d'approcher des aspects peu connus de l'organisation et du fonctionnement du suffrage à cette époque. Le bilan de cet apport n'est donc pas négligeable pour une meilleure connaissance du système politique de la Seconde République et de la période antérieure au coup d'Etat.

\section{Les élections partielles, origine et chronologie}

\section{L'origine diversifiée des élections partielles}

2 Les élections partielles à la Législative se déroulent tout au long des trois années : 1849, 1850 et 1851.31 scrutins sont organisés en 1849 pour pourvoir 42 sièges, 22 scrutins pour 41 sièges en 1850 et, en 1851, 11 scrutins pour 12 sièges; au total 64 scrutins pour 95 sièges, soit $12,7 \%$ des sièges de l'Assemblée législative. Ceux-ci sont répartis entre 41 départements (voir carte 1 ) dont certains ont connu plusieurs scrutins (Seine: 4, Saône-et- Loire : 3, Allier, Ardèche, Charente-Inférieure, Cher, Loire, Loir-et-Cher, Lot, Morbihan, Nièvre, Nord, Seine-et-Mame, Haute-Vienne, Vosges : 2). Il s'agit donc plus que d'un échantillon, d'un ensemble très représentatif, (presque la moitié des départements français), n'excluant aucune grande région.

Les causes de ces élections partielles sont d'ordre très différent. La loi électorale du 15 mars 1849 (article 92) a prévu trois cas principaux de vacance de siège : le décès, la démission, enfin l'option dans le cas où un représentant a été élu dans plusieurs départements - puisque les candidatures multiples sont possibles. Les deux premiers cas sont banals. Les 22 représentants qui moururent pendant la durée de l'Assemblée législative furent remplacés ${ }^{6}$. Parmi eux, quelques personnages connus: le maréchal Bugeaud, l'économiste Frédéric Bastiat, le manufacturier de Seine-Inférieure Grandin, James Demontry, représentant démocrate-socialiste de la Côte-d'Or qui, après le mouvement de juin 1849, s'était réfugié à Cologne. Sept autres démissionnèrent pour des raisons diverses: Rouveure (Ardèche), Ambert (Lot), Henri Wallon (Nord), le général Lahitte (Nord), Louriou (Cher) ${ }^{7}$ l'amiral Romain-Desfossés (Finistère), et Goldenberg (BasRhin). Dans le cas d'élection multiple, le représentant devait faire connaître son choix, son "option ", dans les dix jours qui suivent la déclaration par l'Assemblée de la validité de ces élections. Lors de l'élection générale de mai 1849 , les élections multiples ont été assez nombreuses, à droite comme à gauche: Ledru- Rollin fut élu dans cinq départements, Changamier et Félix Pyat dans trois, 16 autres députés dans deux. Au total 24 sièges dont 11 dans la Seine donnèrent lieu à une option à l'issue des élections du 13 mai 1849, ce qui d'ailleurs n'a rien d'excessif ${ }^{8}$. Ce cas se présenta également plus tard de façon isolée, en Saône-et-Loire, par suite de la double élection de Lamartine dans ce même département et dans le Loiret le 8 juillet 1849, ainsi que dans la Seine, à l'issue de l'élection partielle du 10 mars 1850, du fait de l'élection du démocrate-socialiste Vidal à la fois dans la Seine et le Bas-Rhin.

4 Autres causes de retour aux urnes, liées à la réglementation électorale et beaucoup plus rares, l'inéligibilité d'un candidat, l'annulation des élections ou l'existence d'une incompatibilité. Le premier cas concerna un élu du Loir-et-Cher, Germain Sarrut ${ }^{9}$, en mai 1849, le second, six représentants de la Saône-et-Loire élus lors d'une élection partielle le 10 mars 1850, le troisième, le général Magnan, élu dans la Seine le 8 juillet 1849 et qui, devenant commandant de l'armée de Paris le 15 juillet 1851, dut abandonner son siège de député. Enfin, on mentionnera l'unique cas de deuxième tour nécessité par l'insuffisante 
participation des électeurs à l'élection partielle du 8 juillet 1849 en Charente-Inférieure. Les deux candidats arrivés en tête, Echasseriaux et De la Jusse, n'avaient pas obtenu 1/8 des inscrits comme l'exigeait la loi de 1849, ce qui nécessita un deuxième tour le 22 juillet.

Un dernier cas de vacance est possible et se révélera entre 1849 et 1851, c'est celui de la déchéance de représentants jugés par la Haute-Cour de Justice. Dans ce cas, la vacance effective du siège est beaucoup plus durable puisqu'il faut attendre que le procès soit achevé et les condamnations prononcées pour que la déclaration officielle de vacance soit faite. 31 représentants, parmi lesquels des chefs majeurs de la Montagne furent traduits devant la Haute-Cour de Versailles pour leur participation au mouvement du 13 juin 1849 10. 30 furent condamnés. Leurs sièges, vacants de fait dès le lendemain du 13 juin 1849, ne furent pourvus que le 10 mars $1850^{11}$ sauf un, à Paris, qui, pour cause encore une fois de double élection, donna lieu à un nouveau scrutin le 28 avril 1850 .

Quand la vacance d'un siège est confirmée, la nouvelle élection doit avoir lieu dans un délai de 40 jours, sauf exception pour les départements ou territoires situés outre-mer (Corse, Algérie, Sénégal, Antilles, Guyane, Réunion). Rappelons d'autre part que le mode de scrutin - plurinominal départemental - se transforme automatiquement en un scrutin uninominal s'il n'y a qu'un siège à pourvoir. Même pour un seul siège, tous les électeurs du département sont appelés au scrutin, ce qui renforce la signification des consultations.

Carte 1. Répartition géographique des élections partielles (1849-1851)

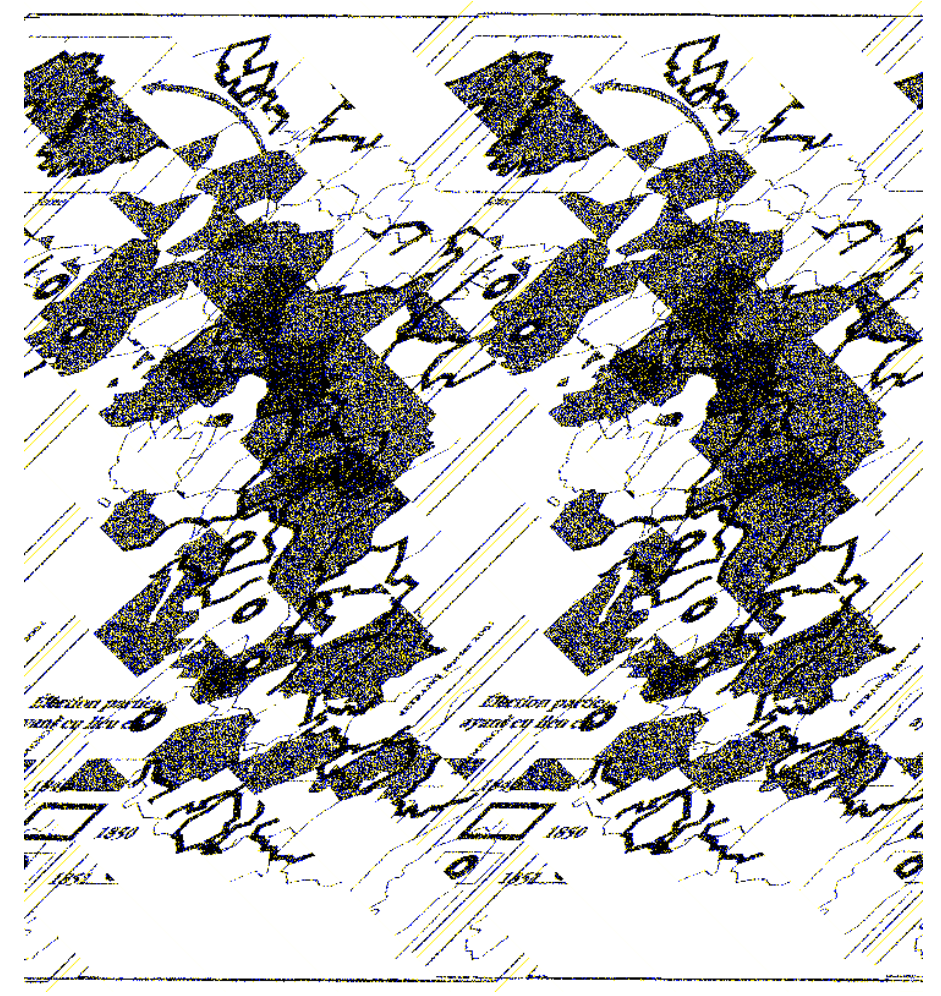

\section{Chronologie et conjoncture des élections partielles}

7 La conjonction de ces diverses causes a déterminé la chronologie des élections partielles. Celle-ci permet de dégager quelques phases essentielles caractérisées à la fois par la 
conjoncture des élections et le nombre de celles-ci, phases séparées par des périodes où les scrutins sont plus rares et isolés.

La première phase se déroule au début de l'été 1849 : elle correspond à la nécessité de remplacer les sièges non pourvus du fait des options consécutives aux élections générales $\mathrm{du} 13 \mathrm{mai}$, auxquels s'ajoutent quelques sièges vacants par décès ou démission. 24 scrutins se déroulent le même jour le 8 juillet 1849 , et l'on peut ajouter à ceux-ci cinq autres qui interviennent le 14 juillet et le 19 août 1849 . Cette première série d'élections se déroule dans une atmosphère politique défavorable aux démocrates-socialistes, d'abord parce qu'ils ont été vaincus aux élections de 1849 , mais surtout parce qu'ils se sont lancés imprudemment dans l'aventure parisienne du 13 juin, et ont perdu une partie de leurs chefs - en fuite comme Ledru-Rollin, Considerant, Martin-Bernard, Pyat, ou emprisonnés comme Suchet et Gambon. Intervenant peu de temps après l'élection générale, ces élections partielles sont également peu motivantes puisqu'elles ne peuvent remettre en question la majorité élue le 13 mai 1849. Elles sont caractérisées par une forte abstention (56,47 \% des inscrits).

9 Trois scrutins plus isolés ont lieu plus tard, le 14 octobre, dans la Gironde, la SeineInférieure et l'Yonne.

10 La seconde phase électorale majeure a lieu dans les six premiers mois de 1850 (22 scrutins). Elle culmine en mars et avril avec, le 10 mars, les quinze scrutins destinés à remplacer les 30 représentants socialistes compromis dans l'affaire du 13 juin 1849 et désormais condamnés par la Haute-Cour et les deux élections du 28 avril, celle de la Seine qui opposa le démocrate Eugène Sue au conservateur Leclerc, et celle de la Saône-et-Loire qui vit le succès de la liste démocrate-socialiste déjà victorieuse le 10 mars, mais invalidée par l'Assemblée. À cette date, les démoc-soc ont eu le temps de panser leurs plaies et de se réorganiser. Et en outre, le conflit entre le président et la droite parlementaire a commencé à se dessiner. La conjoncture des élections du 10 mars 1850 et du 28 avril est donc moins défavorable aux démocrates que celle du 8 juillet 1849. Ces élections mid-term, comme on dirait aujourd'hui, peuvent être un moyen pour l'opinion de sanctionner la politique de la majorité parlementaire ou celle de l'exécutif.

11 Enfin, onze scrutins ont lieu pendant la deuxième moitié de 1850 et en 1851 : ils nous intéressent d'autant plus que, désormais, la loi du 31 mai 1850 est entrée en vigueur ${ }^{12}$. Cette loi ne réduit pas seulement le nombre des électeurs. Elle introduit des nouveautés qui ont des incidences sur les élections partielles. Elle oblige un candidat à obtenir les voix de $25 \%$ des inscrits pour être élu au premier tour (article 13), et étend le délai de vacance d'un siège avant une nouvelle élection à six mois (article 14). C'est ce qui explique par exemple que le siège laissé vacant dans l'Ardèche par le représentant Vasseur, décédé le 5 août 1851, ne fut pas pourvu avant le coup d'Etat. Enfin, elle interdit, par son article 12, le dépouillement séparé des votes militaires (dont la majorité de l'Assemblée se méfiait). Les délais de transmission de ces votes aboutirent souvent à ce qu'ils ne puissent être pris en compte. Événement capital, la loi suscite un débat notamment parmi les démocrates sur le comportement électoral à adopter face à la restriction du suffrage universel. En même temps, l'atmosphère politique générale est empoisonnée par la perspective désormais bien visible du coup d'État. 


\section{Le bilan politique des élections. Vainqueurs et vaincus, révolution des forces politiques à l'Assemblée}

12 Les élections de l'été 1849 , qu'elles résultent des options ou de la vacance de sièges pour d'autres raisons, furent une véritable déroute pour les républicains et encore plus pour les démocrates-socialistes. Elles permirent à la droite de confirmer sa majorité parlementaire. D'une part, tous les sièges libérés par des conservateurs ou des monarchistes ou des bonapartistes furent pourvus par un candidat de la même mouvance d'ensemble et souvent de la même tendance particulière: Crespel de Latouche en Morbihan est remplacé par le monarchiste De Kerdrel, Ney de la Moskowa en Eure-et-Loir par Briffault, chef de cabinet de Louis-Napoléon. Persigny, dans la Loire, cède la place au général de Grammont, dont la bienveillance envers les animaux ne s'étendait pas toujours aux hommes ${ }^{13}$, Delongrais dans le Calvados, à Pierre Leroy-Beaulieu, ancien préfet du Lot et maire de Lisieux, Montalembert dans les Côtes-du-Nord, à Lerioux de Largentay, propriétaire et membre du conseil général, Lacave-Laplagne dans le Gers à un propriétaire désigné par le parti de l'ordre, Lagrange.

13 Les républicains modérés et les démocrates-socialistes remettaient en jeu 18 sièges dont sept dans la Seine. Des treize sièges démocrates- socialistes vacants, un seul revint à un montagnard, celui de Saône-et-Loire, finalement reconquis le 19 août 1849 par le démocrate Joly après l'option de Lamartine (élu le 8 juillet) en faveur du Loiret ${ }^{14}$. Trois des quatre sièges conquis par Ledru-Rollin (en dehors de celui du Var) en mai 1849 sont perdus au profit de la droite ${ }^{15}$ et de même ceux de Mathieu de la Drôme dans ce département, de Michel de Bourges (Haute-Vienne), de Félix Pyat (Nièvre et Seine), de James Demontry dans la Côte-d'Or. Le bilan est un peu moins défavorable pour les républicains modérés : ils perdent leurs cinq sièges sortants - quatre à Paris et celui de Cordier dans le Jura ${ }^{16}$-, mais en revanche récupèrent un siège au détriment des montagnards - celui de Commissaire dans le Rhône, qui passe à Jules Favre.

Les sièges perdus par les républicains ont été gagnés par la droite, mais plutôt par des candidats modérés ou bonapartistes. L'on remarquera que le nombre est assez important, avec la victoire de Lemulier, fidèle de Louis-Napoléon en Côte-d'Or, celle de Napoléon Soult de Dalmatie dans l'Hérault, de Clary, neveu de Joseph Bonaparte en Loir-et-Cher. À Paris, d'autre part, Achille Fould et Ferdinand Barrot ont été élus sur la liste du parti de l'ordre, et en Seine-et-Oise, le bonapartiste Lepic a remplacé Changarnier.

$15 \mathrm{Au}$ total donc, le camp républicain a perdu 16 sièges (dont 12 pour les démocratessocialistes) auxquels s'ajoutent de fait dans l'immédiat ceux des 31 représentants inculpés à la suite du 13 juin soit une perte au moins provisoire de 47 sièges.

16 Les trois élections partielles qui se déroulent en automne, le 14 octobre 1849, marquent au plus un coup d'arrêt à cette déroute. En effet si le manufacturier conservateur Grandin est remplacé en Seine-Inférieure par un autre conservateur, Bourdon, ancien maire d'Elbeuf; si dans l'Yonne, c'est Antoine Bonaparte, frère de Pierre et de Lucien, qui succède à un conservateur modéré, Robert ; les républicains profitent en Gironde, de la division de la droite ${ }^{17}$ et font passer un des leurs, Lagarde avec $49,8 \%$ des votants, résultat qui fut salué avec espoir comme le signe d'un renouveau possible.

17 Les élections partielles de la première moitié de l'année 1850 reflètent- elles un tournant en faveur des démocrates-socialistes? Elles s'étalent entre l'élection du Gard le 13 janvier 
1850 et celle du 9 juin dans le Bas-Rhin qui fut la dernière élection au suffrage universel intégral, avant la mise en application de la loi du 31 mai 1850. Cet ensemble comprend 22 scrutins pour 35 sièges, scrutins qui dans l'ensemble sont un peu plus encourageants pour le camp républicain. Les sortants étaient un légitimiste (Debeaune, Gard), quatre conservateurs - Rouveure (Ardèche), Perreau, (Vosges) Sazerac de Forgés (Charente), et Goldenberg (Bas-Rhin) -, enfin, les 30 démocrates-socialistes déchus de leur mandat par la Haute-Cour de Versailles, qui se répartissaient ainsi : un siège pour l'Allier, l'Ariège, l'Isère, la Loire, la Haute-Loire, le Loir-et-Cher, la Nièvre, les Hautes-Pyrénées, la HauteVienne, deux pour le Cher et le Var, trois pour le Haut-Rhin et la Seine, cinq pour le BasRhin, six pour la Saône-et-Loire.

Examinons d'abord les sièges des cinq sortants de droite. Deux d'entre eux restent dans la même mouvance générale. Celui de Charente est conservé d'ailleurs brillamment (69,7 \% des voix) par le lieutenant-colonel Edgar Ney, aide de camp du président, contre l'ancien constituant Babaud- Larivière. En Ardèche, après la démission du conservateur Rouveure, De la Tourette, légitimiste discret, homme du pays - il habitait Tournon - mais aussi petit-fils de Chaptal, l'emporte avec une nette majorité (57,6\% des voix) sur Hippolyte Camot, au terme d'une campagne extrêmement dure.

Si les autres candidats conservateurs sont battus, cela résulte plus de circonstances particulières que d'un recul avéré de la droite. Dans le Gard, le commandant Favand, démocrate-socialiste d'ailleurs fort modéré, doit son succès comme précédemment dans le cas girondin, aux luttes fratricides qui opposent alors les fractions légitimistes, celle de la majorité du parti d'un côté, celle de la Montagne blanche d'autre part. Au contraire, l'ensemble du camp patriote, y compris d'anciens orléanistes, s'est soudé autour du candidat démocrate, ce qui permet à ce dernier d'approcher la majorité absolue des voix (48,7 \%). Charles Guilgot, dans les Vosges, candidat démocrate, élu par 53,9\% des votants, a bénéficié au moins en partie d'un hasard favorable, son adversaire de droite, le général Raoul, étant décédé quatre jours avant le scrutin. L'interprétation de l'élection du BasRhin où l'agronome Goldenberg, le seul modéré de la députation du département, élu en 1849, avait démissionné, est plus délicate, car le duel attendu entre la droite (un homme de lettres, Charles Muller) et la gauche (l'avocat Liechtenberger, ancien représentant et figure historique du libéralisme avancé et républicanisme) a été perturbé par la candidature de l'inclassable Émile de Girardin, directeur de La Presse, lequel l'emporte avec 51,03\% des voix, prises pour une bonne part à la gauche.

Enfin, mais ceci est plus connu, abordons le cas des 30 sièges répartis dans quinze départements, dont les démocrates-socialistes avaient été déchus à la suite du mouvement insurrectionnel de juin 1849. Presque partout l'élection a donné lieu à des duels entre listes adverses. Trois cas de figure sont perceptibles. Le premier, concernant sept départements, consacre une nette victoire des démocrates-socialistes, qui ne reflète pas forcément un progrès de cette tendance. C'est le cas en Haute-Loire où Francisque Maigne, frère du député déchu, Jules Maigne, remporte facilement l'élection (57,93\% des inscrits), comme dans la Nièvre avec la victoire de Charles Gambon, frère de Ferdinand, condamné et emprisonné ( $54,2 \%$ des votants), en Isère où l'implantation démocratique était solide, et où Dupont de Bussac, ex-constituant obtient un très bon pourcentage (56,13\% des votants), en Loir-et-Cher où le grand propriétaire noble d'Etchégoyen qui défend ici les couleurs de la gauche, triomphe largement ( $55,5 \%$ des votants). Le succès est encore plus probant quand plusieurs sièges sont à pourvoir : ainsi, en Saône-et-Loire, les démocrates-socialistes remportent les six sièges vacants avec $58 \%$ des voix et dans le 
Bas-Rhin, face à une liste nettement bonapartiste, ils en conservent cinq $(56,77 \%$ des voix). La marge victorieuse est plus faible en Haute-Vienne (52,5\%). Un choix judicieux des candidats (on notera le recours assez fréquent à un parent tout proche - souvent le frère- de l'ex-élu), une remarquable discipline de vote, comme dans le Bas-Rhin où moins de 2500 voix sur 55000 séparent le premier du dernier élu, ont contribué à ce résultat.

Dans le second cas, le duel aboutit à un équilibre des forces si serré que quand il y a plusieurs sièges à pourvoir, on assiste parfois à un partage des sièges entre la gauche et la droite; mais le résultat final est quand même une perte de sièges pour la gauche. Dans le Haut-Rhin, la gauche fait passer le manufacturier Kestner, mais perd, faute d'environ 200 voix, deux autres sièges vacants au profit de la droite. Même équilibre, dans le Var, où la droite et la gauche s'équilibrent de telle sorte que sur deux sièges à pourvoir, l'un va au candidat de droite Henri Siméon (32514 voix) et l'autre au candidat de la gauche le notaire Clavier $(32128)$. Vote également serré dans l'Allier où 182 voix séparent le candidat de droite Dufour, avocat à la cour de Cassation, finalement élu, de G. Gallay, démocrate-socialiste, propriétaire au Donjon, chef-lieu du radicalisme local. Dans la Loire où la candidature d'Antide Martin, démoc-soc., avait suscité quelques réticences au sein du camp républicain, il approche tout de même de très près (moins de 1000 voix sur plus de 70000 ) le résultat du candidat du parti de l'ordre, un propriétaire Ernest Anglès. Enfin l'élection de la Seine se traduit par la victoire d'une liste d'union républicaine (Carnot, Vidal et de Flotte), résultat à la fois d'une bonne organisation, de l'union qui avait manqué en mai 1849 et d'une très bonne discipline de vote. Mais la droite se tient très bien, conserve son potentiel électoral, et seulement 4000 voix en moyenne (sur 260000 votants) séparent les deux listes.

Dernier cas enfin, la défaite sans appel des démocrates que l'on constate dans l'Ariège, les Hautes-Pyrénées, le Cher. Dans les deux premiers de ces départements, les positions républicaines étaient fragiles et on ne s'étonne pas tellement qu'elles cèdent dans l'adversité. Partout, la droite a présenté des notables connus, un ancien pair de France, " débris de la Grande Armée ", le général de Pelet (Ariège); un ancien député, De Goulard, dans les Hautes-Pyrénées; deux anciens députés, Poisle-Desgranges et de Vogué, pour le Cher. Les autorités, le préfet Piétri dans l'Ariège notamment, ont pesé sur le scrutin. Une division, certes limitée, du camp républicain dans l'Ariège a encore aggravé la situation ${ }^{18}$. Si l'on fait le bilan global de cette phase électorale de la première moitié de l'année 1850, que deviennent les 35 sièges remis en jeu? Les légitimistes avaient un sortant dans le Gard, ils perdent son siège, mais en récupèrent un dans l'Ardèche. Aucun sortant n'était explicitement bonapartiste. Mais le camp du président sort renforcé du scrutin avec un siège en Charente, et des sympathies bonapartistes manifestes chez le général de Pelet dans l'Ariège. Les conservateurs avaient trois sortants (Vosges, Charente, Bas-Rhin) : à l'issue de l'épreuve électorale, ils détiennent sept sièges (Allier : 1, Haut- Rhin : 2, Ariège : 1, Cher : 2, Hautes-Pyrénées : 1). Les républicains modérés qui n'avaient aucun sortant, ont fait élire Carnot dans la Seine et l'on peut à la rigueur compter dans leurs rangs Emile de Girardin, malgré ses variations politiques. Ajoutons que certains élus présentés comme démoc-soc. ne sont pas très éloignés des républicains modérés : ni Kestner, élu dans le Bas-Rhin, ni Favand, élu dans le Gard, ne sont des parangons de la démocratie sociale.

Enfin les démocrates-socialistes dont 30 élus étaient sortants ne retrouvent que 22 sièges (ceci sans tenir compte des réserves que nous venons d'exprimer sur certains de leurs 
candidats), bilan qui eût été encore moins bon si l'on ne tenait compte que des sièges de sortants (20 sièges conservés).

Ces élections, certes moins favorables pour le parti de l'ordre que celles de juillet 1849, ne justifiaient donc absolument pas l'émotion affichée par les leaders de la droite. Sur le moment même, des analystes sérieux firent la même observation. Le ministre de l'Intérieur Baroche analysant devant l'Assemblée les résultats des élections du 10 mars observait à juste titre : «l'élection du 10 mars a amené ce résultat que dix représentants qui n'avaient pas l'habitude de voter pour le gouvernement ont été remplacés par dix représentants qui paraissent devoir voter avec la majorité $»^{19}$. Dans un article d'analyse électorale, assez neuf pour l'époque par sa précision, La Gazette des Tribunaux indiquait que dans l'ensemble des départements où avait eu lieu le vote du 10 mars, le parti de l'ordre n'avait eu que 16 élus sur 134 sièges en mai 1849 alors qu'il en avait obtenu cette fois 10 sur 28 , et elle remarquait surtout que, même dans les départements où les démocrates-socialistes l'avaient emporté le 10 mars, l'écart de voix avec les conservateurs s'était nettement resserré - comme dans la Nièvre, le Bas-Rhin et la Saône-et-Loire ${ }^{20}$. Ce qui irrita la droite et explique sans doute sa réaction disproportionnée, c'est de constater que les démocrates-socialistes qu'elle croyait très affaiblis, avaient encore un capital de forces (le contraire eût été bien étonnant). Le résultat des élections était d'autant plus représentatif que la participation avait été très forte pour des élections partielles, atteignant $66,97 \%$ en moyenne et dépassant dans sept départements $70 \%$ des inscrits ${ }^{21}$.

Le vote de la loi du 31 mai 1850 modifia profondément la situation politique. Il embarrassa profondément les démocrates qui se divisèrent sur la riposte à apporter : fallait-il continuer à participer aux élections ou s'abstenir pour manifester sa condamnation de la loi.? L'abstention, position de principe, mais aussi solution de facilité, l'emporta, au moins dans la Montagne : « Nous voterons tous ou nous ne voterons aucun [...] nous attendrons 1852 » répétait encore Charles Lagrange à l'Assemblée le 15 novembre 1851. Même dans la droite, les avis sur la loi étaient partagés. Les onze élections ${ }^{22}$ pour douze sièges qui eurent lieu entre novembre 1850 et novembre 1851 , presque toujours provoquées par des décès ou des démissions, permettent d'apercevoir à la fois l'amputation différenciée de l'électorat opérée par la loi du 31 mai et les réactions des électeurs. L'amputation du corps électoral était au maximum dans la Seine $(-63,8 \%$ des électeurs) et restait très forte dans le Nord $(-49,2 \%)$. Elle était la plus faible dans un département très rural comme la Seine-et-Mame $(-17,2 \%)$, mais touchait cependant certains départements ruraux (-42,8\% en Finistère) ce qui inquiétait les légitimistes.

Ailleurs, la diminution se situait dans une fourchette de 27 à $35 \%$. Compte- tenu des consignes d'abstention données par une fraction du camp républicain, l'interprétation des résultats est assez délicate. On se limitera aux faits les plus saillants.

Dans ces onze scrutins, les républicains remettaient en jeu quatre sièges - deux de démocrates-socialistes, ceux de Louriou (Cher) et Coralli, (Haute-Vienne) et deux de modérés, Ducluzeau (Dordogne) et de Saint-Priest (Lot). Ils les perdent tous, soit qu'ils ne livrent pas bataille, soit que l'abstention d'une partie des républicains permette la victoire du camp adverse.

29 C'est donc la droite qui enlève tous les sièges, mais, au sein de celle-ci, les bonapartistes remportent de nouveaux succès en faisant élire successivement dans le Nord deux ministres de Louis-Napoléon, le général La Hitte, puis Vaïsse, et un rallié, Jean Joseph Bidault dans le Cher. 

en tout cas pas assez bien pour empêcher l'élection, au moins au premier tour, ou lui retirer sa légitimité. Il aurait fallu d'abord que le camp républicain soit unanime à appliquer ce mot d'ordre. Or ce ne fut pas le cas : les républicains modérés - dans les Landes par exemple où Eugène Duclerc se présentait- voulurent livrer bataille, même dans les conditions de la nouvelle loi. Les consignes d'abstention n'eurent un succès appréciable que dans le Lot et la Haute-Vienne. Dans le Nord, on compta aussi beaucoup de bulletins blancs et nuls. De plus, le parti de l'ordre averti du péril, s'efforça de mobiliser ses forces. Le résultat fut que pour les dix élections (Seine exceptée) qui se déroulèrent sous l'empire de la nouvelle loi, la participation ne tomba jamais au-dessous de $30 \%$ (30,28\% en Haute-Vienne) et fut en moyenne de $42,18 \%$. Ce chiffre, sans doute inférieur à celui des élections précédentes, était à peu près égal au taux de participation lors des élections de juillet 1849 (43,53\%). D'autre part, la loi du 31 mai 1850 avait fixé à un quart des inscrits le nombre de suffrages nécessaires pour qu'un candidat soit élu au premier tour. Les démocrates qui avaient pu compter sur cette disposition pour rendre l'élection plus difficile furent déçus puisque même le plus défavorisé des candidats de la droite, Bataille, en Haute-Vienne, dépassa ce pourcentage, de justesse d'ailleurs (26,16\%).

Si l'on examine enfin l'incidence de l'ensemble des élections partielles sur la situation des forces politiques à l'Assemblée nationale à la fin de novembre 1851 en faisant le bilan des sièges gagnés et perdus globalement par les différentes forces politiques depuis mai 1849, on constate qu'au total les démocrates socialistes ont perdu 23 sièges et les républicains modérés deux, alors que les conservateurs monarchistes ou en tout cas du parti de l'ordre en ont gagné douze et les bonapartistes treize. Ces nouveaux élus sont aussi pour une bonne part d'anciens députés de la Monarchie censitaire.

On peut donc penser que les élections législatives, si elles avaient eu lieu en 1852 auraient confirmé cette évolution en assurant la victoire au parti de l'ordre, mais en accroissant au sein de celui-ci le poids de la fraction bonapartiste.

\section{Des pratiques électorales en évolution et déjà autoritaires}

Les élections partielles permettent aussi d'apercevoir une évolution des pratiques électorales qui, par certains aspects, en facilite et en régularise l'exercice, mais qui, par d'autres, anticipe sur les méthodes autoritaires du Second Empire. En premier lieu, la législation électorale a été modifiée à la fin de 1849, afin de rapprocher le lieu de vote de l'électeur de base. La loi du 26 décembre 1849 a fixé à 501 habitants (« plus de 500 » dit le texte) le nombre plancher des habitants d'une circonscription électorale, alors que la loi du 15 mars 1849 n'autorisait pas la division du canton en plus de quatre circonscriptions. Ceci a permis dans certains départements de multiplier le nombre des circonscriptions de vote : dans l'Isère qui compte 550 communes, le nombre de circonscriptions passe ainsi de 109 en mai 1849 à 393 pour l'élection du 26 mars $1850^{23}$. Il atteignit 351 dans le Nord en 1851, soit, un peu plus d'une circonscription pour deux communes, 351 également en Saône-et Loire au lieu de 164 auparavant ${ }^{24}$. Dans l'Ardèche, l'application de la même loi aboutit à ce que seules 59 communes ne votent pas sur place en mars $1850^{25}$. Le vote à la commune devient donc peu à peu une réalité. Peut-être d'ailleurs a-t-il contribué à améliorer la participation électorale, au moins dans les dix premiers mois de 1850.

Revue d'histoire du XIXe siècle, 22 | 2001 

un élu au premier tour d'obtenir les suffrages de $25 \%$ des inscrits (article 13 de la loi du 31 mai 1850), incite à une rigueur plus grande dans la publication des chiffres. Les inscrits et les votants sont presque toujours mentionnés désormais dans le rapport fait à l'Assemblée et souvent dans les journaux. Les rapporteurs précisent aussi le nombre de voix obtenues par les principaux candidats à l'élection au lieu de se contenter, comme le rapporteur de l'élection du 8 juillet 1849 dans les Vosges, d'indiquer seulement les suffrages obtenus par le candidat arrivé en tête. Il arrive même qu'ils mentionnent -ce qui est une nouveauté- non plus seulement les «voix perdues", ou les «bulletins inconstitutionnels ", mais les bulletins «blancs et nuls » (Charente, élection du 3 février 1850).

ais, le fait le plus saillant, c'est que les batailles électorales deviennent beaucoup plus rudes et que l'administration prend plus souvent parti contre les opposants démocratessocialistes, ce que montrent nettement les débats, très vifs, à l'occasion de la validation des élections. Ces tendances, déjà apparues lors des élections de mai 1849 se renforcent. En juillet 1849, dans le Loir-et-Cher, dans la lutte qui oppose le républicain Germain Sarrut et le bonapartiste Clary, le ministre de l'Intérieur Dufaure soutient Clary, le souspréfet de Vendôme fait campagne en sa faveur, les gendarmes, à Marchenoir et Cour-surLoire, les gardes-champêtres à Huisseau-sur-Cosson déchirent les affiches de Sarrut, les maires font proclamer son inéligibilitée ${ }^{26}$. L'intervention gouvernementale est très apparente dans les Landes lors de l'élection du 11 mai 1851. Le 9 mai, le ministre de l'Intérieur invite par dépêche le préfet des Landes à faire publier par les sous-préfets l'opinion du gouvernement selon laquelle les amis de l'ordre ne peuvent donner leur voix qu'à un partisan de la loi du 31 mai 1850 - en précisant que c'est le général Durrieu qui répond à cette condition. La dépêche est effectivement affichée à Dax. Madier-Montjau, à l'Assemblée dénonce les pressions sur les fonctionnaires, «tous ces petits malheureux fonctionnaires depuis le juge de paix jusqu'à l'agent-voyer ${ }^{27}$. Les dispositions les plus restrictives de la législation sont mises en avant: ainsi, dans les Hautes-Pyrénées, on utilise un arrêt de la Cour de cassation réservant aux élections générales (et non aux partielles) la dispense d'autorisation pour les affiches électorales prévue par la loi du 21 avril $1849^{28}$. Les préfets - comme dans le Haut-Rhin - n'hésitent pas à interdire le colportage des circulaires du parti démocratique ${ }^{29}$. Ailleurs, le gouvernement se réfère à la loi du 6 juin 1850 qui lui permet d'interdire le cas échéant les réunions électorales.

Le parti de l'ordre aussi se mobilise : en mars 1850, la lutte est très violente en Ardèche. A la Chambre, le député démocrate Gleizal dénonce les pressions du clergé, la substitution des bulletins par les présidents de section électorale, les scrutateurs ou même les gendarmes, l'impossibilité d'afficher pour les partisans de Carnot, alors que le jour même des élections, des affiches calomnieuses et alarmistes contre ce candidat, l'accusant d'être l'ami de Proudhon et de Louis Blanc, ont été posées: «Habitants de l'Ardèche! Voulezvous le triomphe de la république rouge, c'est-à-dire de la guillotine, la ruine de votre industrie, les cocons à $1 \mathrm{~F}$ le demi-kilo, de nouveaux 45 centimes ? Nommons Carnot ${ }^{30}$. Même ton, extrêmement violent, de la droite en Saône-et-Loire en mars 1850 contre Charassin, accusé par Le Courrier de Saône-et-Loire (9 mars 1850) de vouloir «mettre en commun vos femmes et vos enfants, vos bœufs et vos charrues». Dans le même département, on se plaint auprès de l'Assemblée de pressions sur les fermiers ${ }^{31}$. Ainsi, même si ces pressions ne sont pas encore générales, il est significatif de les voir apparaitre et que l'Assemblée les absolve par la validation des scrutins. Les débats de 
validation montrent aussi que l'Assemblée tend à pratiquer deux poids, deux mesures, en fonction des résultats attendus du scrutin. Elle annule l'élection de Saône-et-Loire du 10 mars 1850, malgré la très large majorité obtenue par les démocrates-socialistes, en prétextant que des électeurs inscrits sur les listes depuis l'année 1850 y avaient voté, alors que seules les listes de 1849 aurait du être utilisées. Mais elle ne dit rien du Haut-Rhin où il en a été de même ; et lorsqu'une situation comparable se présente dans le Var, pour un scrutin ayant eu lieu le même jour, elle se contente d'annuler seulement les suffrages incriminés, ce qui permet de faire passer un candidat conservateur. Les pratiques autoritaires qui caractériseront le Second Empire s'insinuaient donc progressivement dans la vie politique de la Seconde République, avant même le coup d'Etat.

\section{Le parti démocratique dans une impasse}

On peut penser que les représentants démocrates-socialistes de l'Assemblée percevaient au moins confusément cette évolution qui leur était défavorable et cela explique sans doute leur prudence. Ils se limitèrent le plus souvent à des actions symboliques comme celle de Schœlcher proposant en août 1851 au nom de la majorité du $13^{\text {ème }}$ bureau, de ne pas valider l'élection du Nord « considérant qu' [elle] a été faite sur des listes où ne sont pas inscrits tous les citoyens du département du Nord jouissant de leurs droits civils et politiques $»^{32}$. Une autre solution, qui répondait peut-être mieux à l'impatience des démocrates était de faire planer la menace d'une intervention populaire en 1852 pour rétablir le suffrage universel. Voyant dans l'abstention massive à l'élection du Nord le 3 novembre 1850, « le premier conflit, la première lutte pacifique entre la constitution qui consacre le suffrage universel et la loi du 31 mai qui l'altère dans son essence ", Michel de Bourges s'écriait: "ce sera aussi l'affaire du peuple en 1852 [...] de faire connaître solennellement sa volonté nouvelle $\aleph^{33}$. De même Pascal Duprat, protestant contre la joie de la droite lors de la validation de l'élection du Cher, le 3 décembre 1850, jetait à la face de ses adversaires: «Nous verrons si vous rirez en $1852 »^{34}$. En novembre 1851, Charles Lagrange annonçait: «le peuple ira voter [en 1852], avec la constitution d'une main et son bulletin de l'autre $\aleph^{35}$. Ces protestations ne sortaient pas de la rhétorique parlementaire. Mais elles pouvaient faire impression sur les masses, favoriser même une certaine impatience qui se traduisait dans les scrutins par des bulletins extrémistes évoquant la guillotine à venir pour les conservateurs ou les "aristos ${ }^{36}$. En réalité, il y avait bien peu de chances que le soulèvement pacifique annoncé pour 1852 pût se produire, sauf dans quelques centres très localisés. C'est pourquoi, dans le parti démocratique, certains comptaient sur le coup d'État pour débloquer la situation et permettre plus facilement l'insurrection libératrice. C'est bien ce qui se produisit, mais le calcul était mauvais, puisqu'au bout du compte, les démocrates en furent les victimes. 
Élections partielles de 1849 (entre le 13 mai, date de l'élection de l'assemblée législative et la fin de l'année). Partie 1

\begin{tabular}{|c|c|c|c|}
\hline \multicolumn{4}{|l|}{ Département } \\
\hline \multicolumn{4}{|l|}{ Date } \\
\hline Cause de l'élection partielle & Inscrits & Votants & $\begin{array}{c}\text { votants/ } \\
\text { inscrits }\end{array}$ \\
\hline $\begin{array}{l}\text { Candidats élus/autres candidats, état et/ou } \\
\text { profession }\end{array}$ & option politique & $\begin{array}{r}\text { voix } \\
\text { obtenues }\end{array}$ & $\begin{array}{r}\% \text { des } \\
\text { votants }\end{array}$ \\
\hline \multicolumn{4}{|l|}{ Allier } \\
\hline \multicolumn{4}{|l|}{8 juillet $1849^{37}$} \\
\hline Remplacement de Ledru-Rollin (option) & 90200 & 31052 & $34,4 \%$ \\
\hline Desmaroux (Gilbert, Désirat) & modéré & 12968 & $41,8 \%$ \\
\hline Gallay & républicain socialiste & 12909 & $41,6 \%$ \\
\hline Thouret & & 4364 & $14,1 \%$ \\
\hline \multicolumn{4}{|l|}{ Ardèche } \\
\hline \multicolumn{4}{|l|}{8 juillet $1849^{38}$} \\
\hline remplacement de Pierre Bonaparte (option) & 100401 & 34719 & $34,5 \%$ \\
\hline Rouveure aîné, mégissier & conservateur & 22406 & $64,5 \%$ \\
\hline Carnot (Hippolyte) & & 7587 & $21,9 \%$ \\
\hline Guiter, ancien préfet & & 3316 & $9,6 \%$ \\
\hline Bouches-du-Rhône & & & \\
\hline
\end{tabular}

Notes: $: 37,38,39$

Élections partielles de 1849 (entre le 13 mai, date de l'élection de l'assemblée législative et la fin de l'année). Partie 2

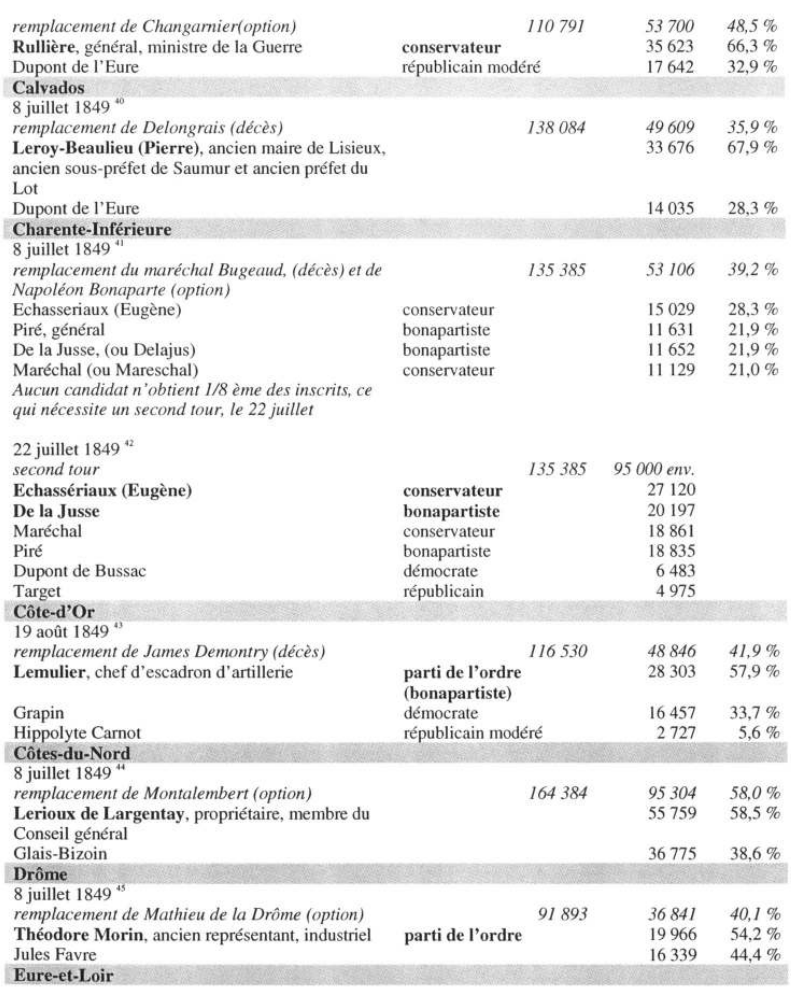

Notes: $40,41,42,43,44,45$ 
Élections partielles de 1849 (entre le 13 mai, date de l'élection de l'assemblée législative et la fin de l'année). Partie 3

\begin{tabular}{|c|c|c|c|}
\hline $\begin{array}{l}8 \text { juillet } 1849^{46} \\
\text { remplacement de Ney de la Moskowa (option) } \\
\text { Briffault, chef de cabinet de Louis-Napoléon } \\
\text { Lamartine } \\
\text { Maunoury }\end{array}$ & bonapartiste & $\begin{array}{r}\text { non fourni } \\
22734\end{array}$ & \\
\hline \multirow{2}{*}{\multicolumn{4}{|c|}{ Gers }} \\
\hline 8 juillet $1849^{47}$ & & & \\
\hline remplacement de Lacave-Laplagne (décès) & 96572 & 41398 & $42,9 \%$ \\
\hline Lagrange (Pierre, Frédéric) & parti de l'ordre & 23703 & $57,3 \%$ \\
\hline $\begin{array}{l}\text { Pégot-Ogier, ancien commissaire du département, } \\
\text { ancien représentant }\end{array}$ & montagnard & 13897 & $33,6 \%$ \\
\hline Alem-Rousseau, ancien constituant & républicain modéré & 2286 & $5,5 \%$ \\
\hline David, ancien constituant & légitimiste & 1512 & $3,7 \%$ \\
\hline \multicolumn{4}{|l|}{ Gironde } \\
\hline \multicolumn{4}{|l|}{14 octobre $1849^{* *}$} \\
\hline Lagarde, avocat à Bordeaux, ancien constituant & $\begin{array}{l}\text { candidat d'union } \\
\text { républicaine }\end{array}$ & 35933 & $49,6 \%$ \\
\hline Gautier & orléaniste & 26304 & $36,3 \%$ \\
\hline Ravez fils & légitimiste & 9071 & $12,5 \%$ \\
\hline \multicolumn{4}{|l|}{ Hérault } \\
\hline $\begin{array}{l}8 \text { juillet } 1849^{\text {th }} \\
\text { remplacement de Ledru-Rollin (option) }\end{array}$ & 121933 & $56523^{50}$ & $46,4 \%$ \\
\hline Soult de Dalmatie & parti de l'ordre & 37019 & $65,5 \%$ \\
\hline Flocon & démocrate & 20822 & $36,8 \%$ \\
\hline \multicolumn{4}{|l|}{ Jura } \\
\hline \multicolumn{4}{|l|}{8 juillet $1849^{\text {s1 }}$} \\
\hline remplacement de Cordier (décès) & 90000 env. & 40000 env. & \\
\hline Valette, ancien constituant & conservateur & 18873 & \\
\hline Ribeyrolles & démocrate & 16622 & \\
\hline Lamartine & modéré & 3329 & \\
\hline \multicolumn{4}{|l|}{ Loire } \\
\hline \multicolumn{4}{|l|}{22 juillet $1849^{52}$} \\
\hline remplacement de Fialin de Persigny (option) & 118363 & 49794 & $42,1 \%$ \\
\hline général de Grammont & parti de l'ordre & 28970 & $58,2 \%$ \\
\hline Antide Martin & démocrate & 20024 & $40,2 \%$ \\
\hline \\
\hline \multicolumn{4}{|l|}{$\begin{array}{l}8 \text { juillet } 1849^{33} \\
\text { remplacement de Roger (décès) }\end{array}$} \\
\hline Lamartine & modéré & 23006 & $69,0 \%$ \\
\hline Madier de Montjau & démocrate & 7309 & $21,9 \%$ \\
\hline Rondeau & & 2007 & $6,0 \%$ \\
\hline Loir-et-Cher & & & \\
\hline
\end{tabular}

Notes : $46,47,48,49,50,51,52,53$ 
Élections partielles de 1849 (entre le 13 mai, date de l'élection de l'assemblée législative et la fin de l'année). Partie 4

\begin{tabular}{|c|c|c|c|c|}
\hline \multicolumn{5}{|l|}{8 juillet $1849^{4}$} \\
\hline annulation d'élection pour inéligiblité & \multirow{6}{*}{ républicain } & \multirow[t]{5}{*}{69600} & 30804 & $44.3 \%$ \\
\hline $\begin{array}{l}\text { Clary, candidat des comités napoléoniens, neveu } \\
\text { de Joseph Bonaparte }\end{array}$ & & & 14647 & $47,5 \%$ \\
\hline Germain Sarrut & & & 13537 & $43,9 \%$ \\
\hline Ducoux & & & 2009 & $6,5 \%$ \\
\hline divers & & & 611 & $2,0 \%$ \\
\hline \multicolumn{4}{|l|}{ Lot } & \\
\hline \multicolumn{5}{|l|}{8 juillet $1849^{s 5}$} \\
\hline $\begin{array}{l}\text { remplacement d'Ambert, ancien constituant. } \\
(\text { démission }\end{array}$ & \multirow{7}{*}{$\begin{array}{l}\text { conservateur } \\
\text { démocrate }\end{array}$} & \multirow[t]{3}{*}{90017} & 31556 & $35,1 \%$ \\
\hline Verninac, contre-amiral & & & 18704 & $59,3 \%$ \\
\hline Ribeyrolles & & & 12575 & $39,8 \%$ \\
\hline \multirow{2}{*}{\multicolumn{4}{|c|}{$\begin{array}{l}\text { Maine-et-Loire } \\
8 \text { juillet } 1849^{36}\end{array}$}} & \\
\hline 8 juillet $1849^{56}$ & & & & \\
\hline $\begin{array}{l}\text { remplacement d'Oudinot (option) } \\
\text { reme }\end{array}$ & & 148388 & 63612 & $42,9 \%$ \\
\hline amiral Dupetit-Thouars & & & 51646 & $81,2 \%$ \\
\hline \multicolumn{5}{|l|}{ Morbihan } \\
\hline 8 juillet $1849^{37}$ & \multirow{5}{*}{$\begin{array}{l}\text { monarchiste } \\
\text { modéré }\end{array}$} & \multirow{5}{*}{116484} & & \\
\hline remplacement de Crespel de Latouche (décès) & & & 50000 env. & \\
\hline Paul de Kerdrel & & & 42565 & \\
\hline Lamartine & & & 5558 & \\
\hline Cadoudal & & & 2698 & \\
\hline \multicolumn{5}{|l|}{ Nièvre } \\
\hline \multicolumn{5}{|l|}{8 juillet $1849^{5 *}$} \\
\hline remplacement de Félix Pyat (option) & \multirow{4}{*}{$\begin{array}{l}\text { conservateur } \\
\text { démocrate }\end{array}$} & \multirow[t]{3}{*}{84182} & 35967 & $42,7 \%$ \\
\hline Manuel aîné, ancien représentant & & & 18483 & $51.4 \%$ \\
\hline Mouton ex-lieutenant-colonel & & & 16264 & $45,2 \%$ \\
\hline & \\
\hline \multicolumn{5}{|l|}{$\begin{array}{l}\text { Konone } \\
8 \text { juillet } 1849^{\text {s\% }}\end{array}$} \\
\hline remplacement de Commissaire (option) & \multirow{4}{*}{\multicolumn{2}{|c|}{$\begin{array}{l}154253 \\
\text { républicain modéré }\end{array}$}} & 81646 & $52,9 \%$ \\
\hline Jules Favre & & & 41347 & $50,6 \%$ \\
\hline Rivet & & & 27391 & $33,5 \%$ \\
\hline De Mortemart & & & 11739 & $14.4 \%$ \\
\hline \\
\hline \multicolumn{5}{|l|}{$\begin{array}{l}\text { Saonee-et-Loire } \\
8 \text { juillet } 1849^{60}\end{array}$} \\
\hline remplacement de Ledru-Rollin (option) & \multirow{3}{*}{$\begin{array}{l}\text { modéré } \\
\text { démocrate }\end{array}$} & \multirow{3}{*}{149588} & 50371 & $33,7 \%$ \\
\hline Lamartine & & & 29093 & $57,8 \%$ \\
\hline Joly, ancien constituant & & & 20068 & $39,8 \%$ \\
\hline \multicolumn{5}{|l|}{19 août $1849^{61}$} \\
\hline remplacement de Lamartin & & 150253 & 55680 & $37,1 \%$ \\
\hline Joly père, ancien représentant & & & 28433 & $51,1 \%$ \\
\hline Dariot, juge de paix, ancien représentant & \multirow{3}{*}{\multicolumn{2}{|c|}{ républicain modéré }} & 25697 & $46,2 \%$ \\
\hline Mathieu, instituteur & & & 554 & $1,0 \%$ \\
\hline illisibles, blancs, inconstitutionnels & & & 996 & $18 \%$ \\
\hline
\end{tabular}

Notes: $54,55,56,57,58,59,60,61$ 
Élections partielles de 1849 (entre le 13 mai, date de l'élection de l'assemblée législative et la fin de l'année). Partie 5

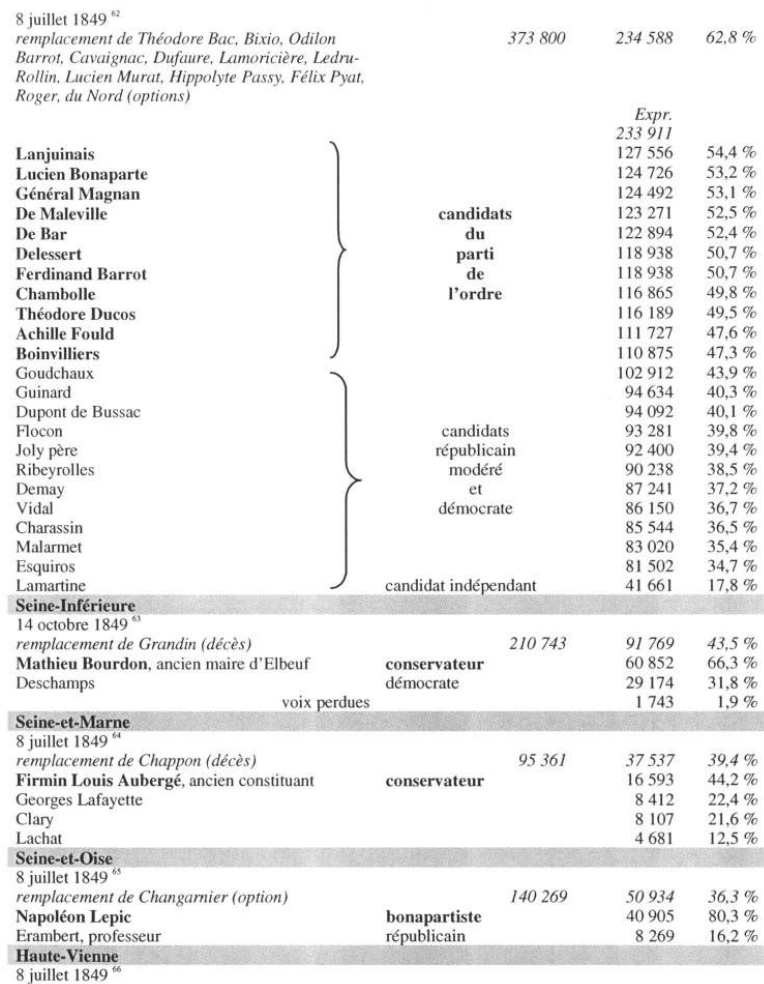

8 juillet 1849

Notes : $62,63,64,65,66$

Élections partielles de 1849 (entre le 13 mai, date de l'élection de l'assemblée législative et la fin de l'année). Partie 6

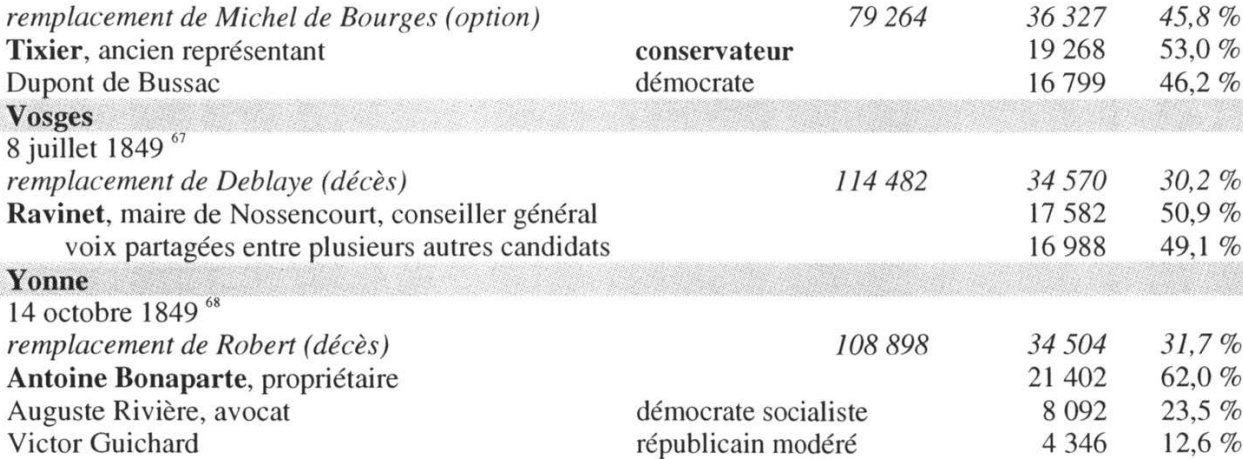

Notes : 67,68 
Élections partielles de 1850 (jusqu'à la première application de la loi du 31 mai 1850 en matière d'élection législative, le 3 novembre de la même année). Partie 1

\begin{tabular}{|c|c|c|c|}
\hline \multicolumn{4}{|l|}{ Département } \\
\hline \multicolumn{4}{|l|}{ Date } \\
\hline Cause de l'élection partielle & \multirow[b]{2}{*}{ option politique } & Votants & $\begin{array}{c}\text { votants/ } \\
\text { inscrits }\end{array}$ \\
\hline $\begin{array}{l}\text { Candidats élus/autres candidats, état et/ou } \\
\text { profession }\end{array}$ & & $\begin{array}{r}\text { voix } \\
\text { obtenues }\end{array}$ & $\begin{array}{r}\% \text { des } \\
\text { votants }\end{array}$ \\
\hline \multicolumn{4}{|l|}{ Allier } \\
\hline $\begin{array}{l}10 \text { mars } 1850^{69} \\
\text { remplacement de Fargin-Fayolle (déchéance) }\end{array}$ & \multirow[t]{3}{*}{89350} & 60575 & $67,8 \%$ \\
\hline Dufour, avocat à la Cour de cassation & & 30087 & $49,7 \%$ \\
\hline G. Gallay, propriétaire, Le Donjon & & 29905 & $49,4 \%$ \\
\hline \multicolumn{4}{|l|}{ Ardèche } \\
\hline \multicolumn{4}{|l|}{10 mars $1850^{70}$} \\
\hline remplacement de Rouveure (démission) & \multirow{3}{*}{$\begin{array}{l}\text { légitimiste } \\
\text { républicain modéré }\end{array}$} & 65261 & $63,3 \%$ \\
\hline Marie Félix Imbault de la Tourette, propriétaire & & 37549 & $57,5 \%$ \\
\hline Hippolyte Carnot & & 27622 & $42,3 \%$ \\
\hline \multicolumn{4}{|l|}{ Ariège } \\
\hline \multicolumn{4}{|l|}{10 mars $1850^{71}$} \\
\hline Général Pelet & parti de l'ordre & 34923 & $65,9 \%$ \\
\hline Aristide Pilhes & démocrate socialiste & 15599 & $29,4 \%$ \\
\hline $\begin{array}{l}\text { Théophile Sylvestre, ancien commissaire adjoint } \\
\text { de } 1848\end{array}$ & & 1408 & $2,7 \%$ \\
\hline
\end{tabular}

Notes: $69,70,71$

Élections partielles de 1850 (jusqu'à la première application de la loi du 31 mai 1850 en matière d'élection législative, le 3 novembre de la même année). Partie 2

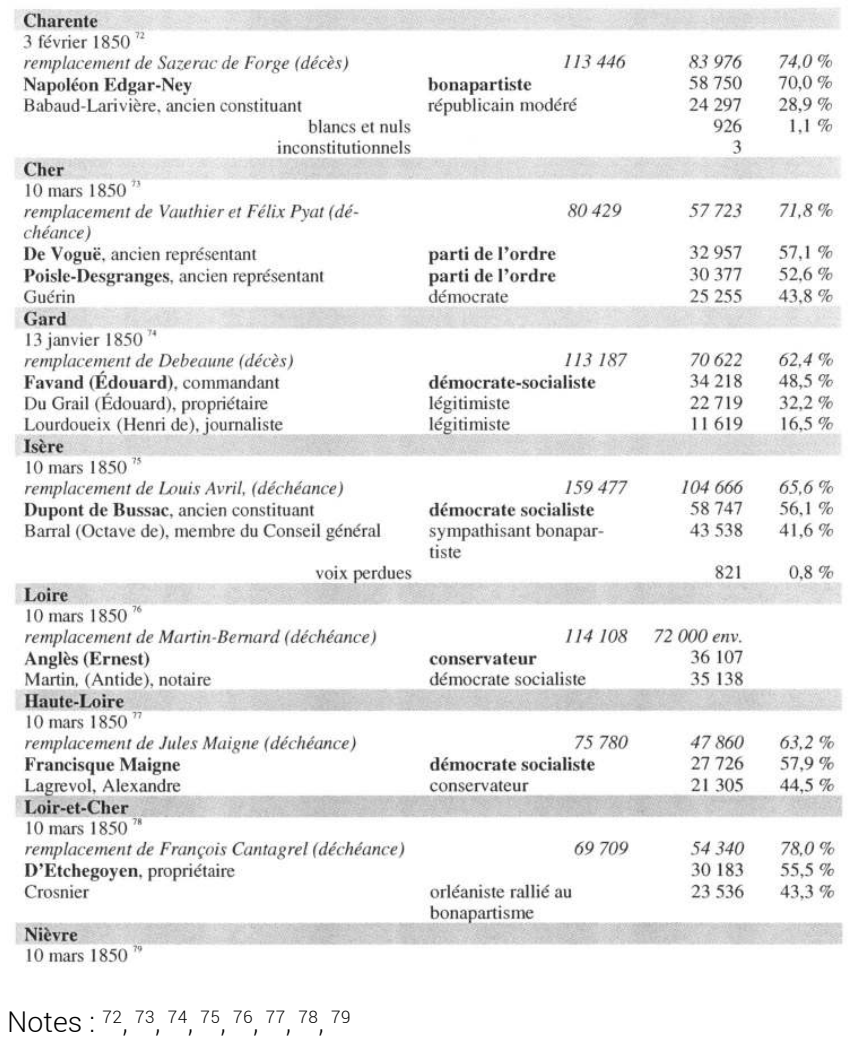


Élections partielles de 1850 (jusqu'à la première application de la loi du 31 mai 1850 en matière d'élection législative, le 3 novembre de la même année). Partie 3

\begin{tabular}{|c|c|c|c|}
\hline remplacement de Ferdinand Gambon (déchéance) & 84182 & 61110 & $72,6 \%$ \\
\hline Gambon (Charles), médecin & démocrate-socialiste & 33144 & $54,2 \%$ \\
\hline Grangier de la Marinière & conservateur & 27717 & $45,4 \%$ \\
\hline voix perdues & & 249 & $0,4 \%$ \\
\hline \multicolumn{4}{|l|}{ Hautes-Pyrénées } \\
\hline \multicolumn{4}{|l|}{10 mars $1850^{10}$} \\
\hline $\begin{array}{l}\text { remplacement de Jean Marie Joseph Deville } \\
\text { (déchéance) }\end{array}$ & 69361 & $5035 I$ & $72,6 \%$ \\
\hline De Goulard (Eugène), ancien député, avocat & conservateur & 27391 & $54,4 \%$ \\
\hline Deville (Louis) & & 22291 & $44,3 \%$ \\
\hline \multicolumn{4}{|l|}{ Bas-Rhin } \\
\hline 10 mars $1850^{\prime \prime \prime}$ & & & \\
\hline $\begin{array}{l}\text { remplacement de Anstett, Beyer, Boch, Commis- } \\
\text { saire, Kopp(déchéance) }\end{array}$ & 137534 & 97491 & $70,9 \%$ \\
\hline \multirow{2}{*}{\multicolumn{4}{|c|}{ Colmar }} \\
\hline & & & \\
\hline Valentin (Édouard), sous-lieutenant en non- & & 55181 & $56,6 \%$ \\
\hline activité au $6^{\circ}$ bataillon de chasseurs à pied & & & \\
\hline \multirow{2}{*}{\multicolumn{4}{|c|}{ Strasbourg }} \\
\hline & & & \\
\hline Hochstuhl, instituteur, Strasbourg & & 54406 & $55,8 \%$ \\
\hline Sadoul, médecin à Wœrth & & 50214 & $51,5 \%$ \\
\hline Grün (Alphonse) & & 50039 & $51,3 \%$ \\
\hline Daru (Paul), ancien député & & 49928 & $51,2 \%$ \\
\hline Coulman, propriétaire à Brumath & & 49723 & $51,0 \%$ \\
\hline Menneval (Louis-Napoléon) officier d'ordonnance & & 49594 & $50,9 \%$ \\
\hline \multicolumn{4}{|l|}{9 juin $1850^{n 2}$} \\
\hline $\begin{array}{l}\text { remplacement de Goldenberg (démission) } \\
\text { remplo }\end{array}$ & 145995 & & \\
\hline Girardin (Émile de,) directeur de La Presse & & 37566 & $51,0 \%$ \\
\hline Muller (Charles), homme de lettres & & 29539 & $40,1 \%$ \\
\hline Liechtenberger père, ancien représentant, avocat & & 13057 & $17,7 \%$ \\
\hline \multicolumn{4}{|l|}{ Haut-Rhin } \\
\hline $10 \operatorname{mars} 1850^{\prime \prime}$ & & & \\
\hline $\begin{array}{l}\text { remplacement de Hofer, Kanig. Pflieger (dé- } \\
\text { chéance) }\end{array}$ & 121053 & 89791 & $74,2 \%$ \\
\hline Kestner, industriel & démocrate & 44502 & $49,6 \%$ \\
\hline Dolfus & conservateur & 44202 & $49,2 \%$ \\
\hline Migeon & conservateur & 43763 & $48,7 \%$ \\
\hline Jaeger, médecin & républicain, fouriériste & 43582 & $48.5 \%$ \\
\hline Georges & démocrate-socialiste & 42576 & $48,5 \%$ \\
\hline De Berckheim & conservateur & 43528 & $48,5 \%$ \\
\hline \multicolumn{4}{|l|}{ Saône-et-Loire } \\
\hline \multirow{3}{*}{$\begin{array}{l}10 \text { mars } 1850^{*} \\
\text { remplacement de Heitzmann, Jannot, Landolphe, } \\
\text { Ménand, Rolland, Rougeot (déchéance) } \\
\text { Madier de Montjau, aîné }\end{array}$} & & & \\
\hline & 157148 & 105573 & $67,2 \%$ \\
\hline & démocrate-socialiste & 61412 & $58,2 \%$ \\
\hline
\end{tabular}

Notes : $80,81,82,83,84$ 
Élections partielles de 1850 (jusqu'à la première application de la loi du 31 mai 1850 en matière d'élection législative, le 3 novembre de la même année). Partie 4

\begin{tabular}{|c|c|c|c|}
\hline Esquiros & démocrate-socialiste & 61351 & $58,1 \%$ \\
\hline Charassin & démocrate-socialiste & 61321 & \\
\hline Buvignier & démocrate-socialiste & 61315 & \\
\hline Dain & démocrate-socialiste & 61285 & $58,0 \%$ \\
\hline Hennequin & démocrate-socialiste & 61116 & $57,9 \%$ \\
\hline Dariot & modéré & 44568 & $42,2 \%$ \\
\hline Daumas & & 44540 & $42,2 \%$ \\
\hline Chamborre & & 44440 & $42,1 \%$ \\
\hline Boutelier & & 44294 & $42,0 \%$ \\
\hline Lafouge & & 44212 & $41,9 \%$ \\
\hline D'Esterno & & 44094 & $41,8 \%$ \\
\hline \multicolumn{4}{|l|}{28 avril $1850^{* 5}$} \\
\hline $\begin{array}{l}\text { nouveau scrutin par suite de l'annulation de } \\
\text { l'élection précédente }\end{array}$ & 154015 & 120162 & $78,0 \%$ \\
\hline Madier-Montjau aîné & démocrate-socialiste & 73109 & $60,8 \%$ \\
\hline Esquiros (Alphonse) & démocrate-socialiste & 73060 & $60,8 \%$ \\
\hline Charassin (Frédéric) & démocrate-socialiste & 73014 & $60,8 \%$ \\
\hline Dain (Charles) & démocrate-socialiste & 73003 & $60,8 \%$ \\
\hline Hennequin (Victor) & démocrate-socialiste & 72822 & $60,6 \%$ \\
\hline Colfavru & démocrate-socialiste & 71290 & $59,3 \%$ \\
\hline Billault & (droite, ler non élu) & 46508 & $38,7 \%$ \\
\hline \multicolumn{4}{|l|}{ Seine } \\
\hline $\begin{array}{l}10 \text { mars } 1850^{* 0} \\
\text { remplacement de Considérant, Boischot, Rattier }\end{array}$ & 353509 & 260198 & $73,6 \%$ \\
\hline \multicolumn{4}{|l|}{ (déchéance) $\quad$ suffrages non comptés } \\
\hline Carnot (Hippolyte) & & 132797 & $50,5 \%$ \\
\hline Vidal (François) & & 128439 & $48,8 \%$ \\
\hline De Flotte & & 126643 & $48,2 \%$ \\
\hline Foy & & 125648 & $47,8 \%$ \\
\hline Lahitte & & 125478 & $47,7 \%$ \\
\hline Bonjean & & 124347 & $47,3 \%$ \\
\hline \multicolumn{4}{|l|}{28 avril $1850^{\prime \prime}$} \\
\hline remplacement de F. Vidal (option) & 324369 & 250609 & $77,3 \%$ \\
\hline Sue (Eugène) & & 127883 & $51,0 \%$ \\
\hline Leclerc & & 119748 & $47,8 \%$ \\
\hline \multicolumn{4}{|l|}{ Var } \\
\hline $\begin{array}{l}10 \text { mars } 1850 " \\
\text { remplacement de Ledru-Rollin et Fulcran Suchet } \\
\text { (déchéance) }\end{array}$ & 101515 & 58807 & $57,9 \%$ \\
\hline Siméon (Henri) & parti de l'ordre & 32500 & $55,3 \%$ \\
\hline Clavier, notaire & démocrate-socialiste & 32128 & $54,6 \%$ \\
\hline De Clappiers & parti de l'ordre & 32116 & $54,6 \%$ \\
\hline Suchet (Pierre) & & 31629 & $53,8 \%$ \\
\hline
\end{tabular}

Notes : $85,86,87,88,89$

Élections partielles de 1850 (jusqu'à la première application de la loi du 31 mai 1850 en matière d'élection législative, le 3 novembre de la même année). Partie 5

remplacement de Guillaume Daniel-Lamazière (déchéance)

Ducoux, ancien constituant

Bataille, officier

Vosges

24 mars $1850^{90}$

remplacement de Perreau (décès)

Guilgot (Charles), propriétaire, Epinal général Raoul

\begin{tabular}{|c|c|c|}
\hline 76922 & 56394 & $73,3 \%$ \\
\hline démocrate-socialiste & 29619 & $52,5 \%$ \\
\hline bonapartiste & 26651 & $47,3 \%$ \\
\hline 114099 & 62232 & $54,5 \%$ \\
\hline démocrate & 33544 & $53,9 \%$ \\
\hline conservateur & 26720 & $42,9 \%$ \\
\hline
\end{tabular}

Note : 90 


\section{Élections partielles du 3 novembre 1850 au 30 novembre 1851. Partie 1}

\begin{tabular}{|c|c|c|c|}
\hline \multicolumn{4}{|l|}{ Département } \\
\hline \multicolumn{4}{|l|}{ Date } \\
\hline Cause de l'élection partielle & Inscrits & Votants & $\begin{array}{c}\text { votants/ } \\
\text { inscrits }\end{array}$ \\
\hline Candidats élus/autres candidats, état et/ou profession & option politique & $\begin{array}{r}\text { voix obte- } \\
\text { nues }\end{array}$ & $\begin{array}{r}\% \text { des } \\
\text { votants }\end{array}$ \\
\hline \multicolumn{4}{|l|}{ Cher } \\
\hline $\begin{array}{l}24 \text { novembre } 1850^{91} \\
\text { remplacement de Poisle-Desgranges (décès) et de } \\
\text { Louriou (démission) }\end{array}$ & 55768 & 27405 & $49,1 \%$ \\
\hline $\begin{array}{l}\text { Duvergier de Hauranne (Prosper, Léon), ancien } \\
\text { constituant, conseiller général du Cher }\end{array}$ & & 17154 & $62,6 \%$ \\
\hline Bidault, ancien représentant, avocat & & 16791 & $61,3 \%$ \\
\hline Planchat, maire de Bourges & & 9238 & $33,7 \%$ \\
\hline Guillot, avocat & & 8633 & $31,5 \%$ \\
\hline voix perdues et bulletins blancs & & 1465 & $5,3 \%$ \\
\hline \multicolumn{4}{|l|}{ Dordogne } \\
\hline \multicolumn{4}{|l|}{6 juillet $1851^{92}$} \\
\hline remplacement de Ducluzeau (décès) & 105215 & 43962 & $41,8 \%$ \\
\hline Magne, ministre des Travaux publics & conservateur & 40043 & $91,1 \%$ \\
\hline Caylus & & 214 & $0,5 \%$ \\
\hline Taillefer & & 149 & $0,3 \%$ \\
\hline divers autres candidats & & 3526 & $8,0 \%$ \\
\hline \multicolumn{4}{|l|}{ Finistère } \\
\hline $\begin{array}{l}21 \text { septembre } 1851^{93} \\
\text { remplacement de l'amiral Romain-Desfossés (démis- } \\
\text { sion) }\end{array}$ & 88466 & 34246 & $38,7 \%$ \\
\hline De Kersauson-Pennendreff & légitimiste & 23919 & $69,8 \%$ \\
\hline De Gasté & $\begin{array}{l}\text { républicain } \\
\text { modéré }\end{array}$ & 7897 & $23,1 \%$ \\
\hline voix perdues & & 2430 & $7,1 \%$ \\
\hline \multicolumn{4}{|l|}{ Landes } \\
\hline $\begin{array}{l}11 \text { mai } 1851^{94} \\
\text { remplacement de Frédéric Bastiat (décès) }\end{array}$ & $\begin{array}{r}55303 \\
\end{array}$ & 29267 & $52,9 \%$ \\
\hline Durrieu, général de division en retraite & parti de l'ordre & 17802 & $60,8 \%$ \\
\hline
\end{tabular}

Notes : $91,92,93,94$

Élections partielles du 3 novembre 1850 au 30 novembre 1851. Partie 2

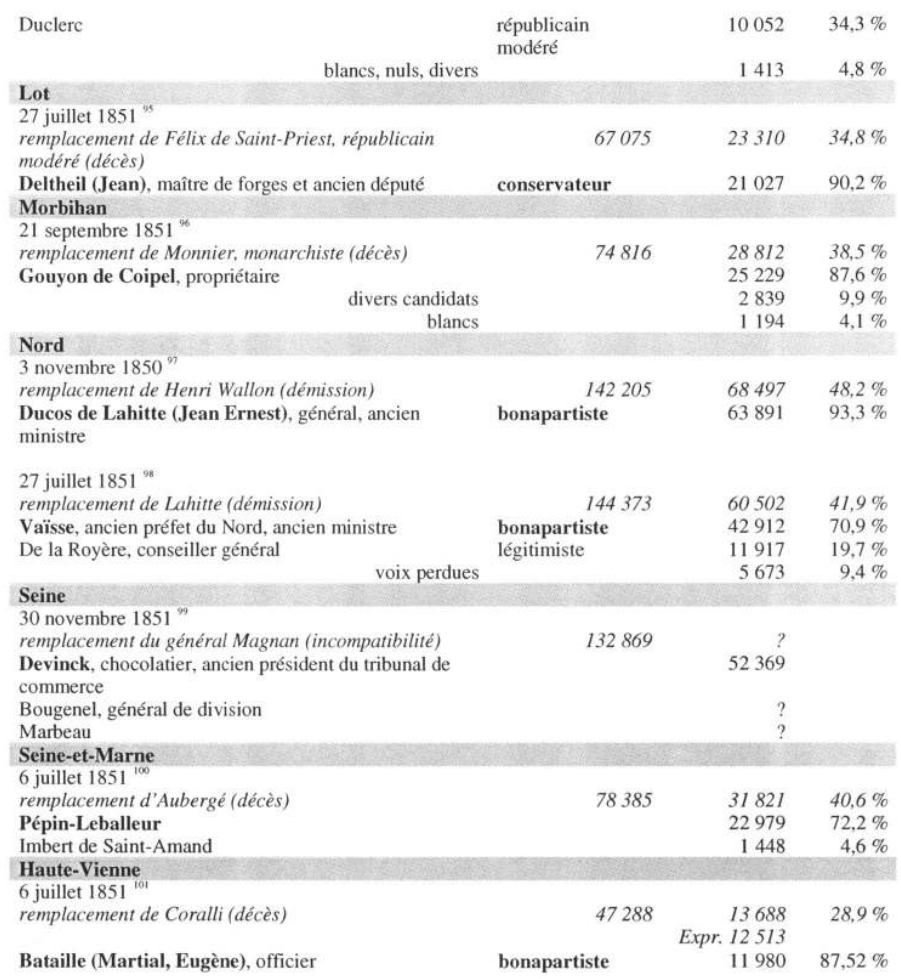

Notes : 95, 96, 97, 98, 99, 100, 101 


\section{NOTES}

1. Jacques GOUAULT, Comment la France est devenue républicaine 1870-75. Les élections générales et partielles à l'Assemblée nationale 1870-75, Paris, Presses de Sciences Po, 1954, 193 p. 2. Jacques GOUAULT, Comment la France est devenue républicaine 1870-75. Les élections générales et partielles à l'Assemblée nationale 1870-75, Paris, Presses de Sciences Po, 1954, 193 p. 2. On en trouvera les références pour chaque département dans la liste des résultats en fin de cet article. Pour situer ces élections partielles dans l'ensemble des expériences électorales de la Seconde République, voir Raymond HUARD, "Le suffrage "universel" sous la Seconde République, état des travaux, questions en attente » dans Revue d'histoire du XIX siècle, no 14 , 1997, pp. 51-72. Dans l'article que nous présentons aujourd'hui, nous avons été conduit à modifier légèrement, à la suite d'une étude plus fouillée, certaines données de cet article.

3. Il est impossible ici de mentionner toutes les allusions aux élections partielles, présentes dès les premières grandes histoires de la Seconde République comme celle de Victor PIERRE, Histoire de la République de 1848, Paris, Éditions Pion, 1873-78, ou de Pierre de la GORCE, Histoire de la seconde république française, Paris, Éditions Pion, Nourit et Cie, 1887. Signalons cependant l'apport de Patrice CHAMOUARD, Paris en décembre 1851, le comportement des représentants montagnards, Mémoire de maîtrise sous la direction de Philippe Vigier, Université Paris 10, 1974, $213 \mathrm{f}$.

4. Rémi GOSSEZ, «Notes sur la composition et l'attitude politique de la troupe », dans Bibliothèque de la révolution de 1848, Études, tome 18, La Roche-sur-Yon, 1955, p. 77-110.

5. Nous avons utilisé, outre les études locales déjà mentionnées, les débats de validation des élections publiés au Moniteur universel ainsi que les résultats donnés par d'autres journaux (Le Siècle, La Gazette des Tribunaux) et nous les avons complétés quand cela paraissait nécessaire par la consultation des dossiers de ces mêmes scrutins aux Archives nationales, sous les cotes $\mathrm{C} 1468$ à 1482.

6. Delongrais (Calvados), Sazerac de Forgés (Charente), Maréchal Bugeaud (Charente-inférieure), Poisle-Desgranges (Cher), Demontry (Côte-d'Or), Ducluzeau (Dordogne), Debeaune (Gard), Lacave-Laplagne (Gers), Ravez (Gironde), Cordier (Jura), Bastiat (Landes), Roger (Loiret), Félix de Saint-Priest (Lot), Crespel de Latouche (Morbihan), Monnier (Morbihan), Aubergé (Seine-etMame), Chappon (Seine-et-Marne), Grandin (Seine-Inférieure), Coralli (Haute-Vienne), Déblayé (Vosges), Perreau (Vosges), Robert (Yonne). Notons que la très grande majorité de ces représentants (Coralli et Demontry faisant exception) étaient des conservateurs ou des monarchistes.

7. Louriou, député du Cher sur la liste démocrate-socialiste, en 1849 avait été poursuivi après le mouvement du 13 juin 1849, mais acquitté. Il préféra démissionner et reprendre sa profession d'avocat.

8. Allier (Ledru-Rollin), Bouches-du-Rhône (Changamier), Charente-Inférieure (Napoléon Bonaparte), Côtes-du-Nord (Montalembert), Drôme (Mathieu de la Drôme), Eure-et-Loir (Ney), Hérault (Ledru-Rollin), Maine-et Loire (Oudinot), Nièvre (F. Pyat), Rhône (Commissaire), Saôneet-Loire (Ledru-Rollin), Seine (Ledru-Rollin, Lucien Murât, Lamoricière, Dufaure, Félix Pyat, Hippolyte Passy, Bixio, Odilon Barrot, Théodore Bac, Cavaignac, Roger, (du Nord), Seine-et-Oise (Changamier), Haute-Vienne (Michel de Bourges).

9. Germain Sarrut avait été mis en faillite en 1845.

10. Ce sont Fargin-Fayolle (Allier), Victor Pilhes (Ariège), Louriou, Félix Pyat et Vauthier (Cher), Louis Avril (Isère), Martin-Bemard (Loire), Jules Maigne (Haute-Loire), Cantagrel (Loir-et Cher), 
Gambon (Nièvre), Deville (Hautes-Pyrénées), Anstett, Beyer, Boch, Commissaire, Kopp (Bas-Rhin), Kœnig, Hofer, Pflieger (Haut-Rhin), Heitzmann, Jannot, Landolphe, Ménand, Rolland, Rougeot, (Saône-et-Loire), Daniel-Lamazière (Haute-Vienne), Boischot, Considerant, Rattier (Seine), LedruRollin et Fulcran Suchet (Var). Seul Louriou fut acquitté.

11. Les élections partielles du 10 mars 1850 concernèrent aussi le remplacement d'un représentant conservateur de l'Ardèche démissionnaire, Rouveure (soit 31 sièges au total), ce qui créa parfois une petite confusion.

12. La loi du 31 mai 1850 entra en vigueur - pour un scrutin législatif - avec l'élection partielle du 3 novembre 1850 dans le Nord.

13. Commandant une brigade de l'armée des Alpes cantonnée dans la Loire en juin 1849, au moment du mouvement de Lyon, le général de Grammont avait annoncé que les voleurs pris en flagrant délit seraient fusillés sans jugement.

14. Lamartine pourrait être considéré comme un républicain modéré, mais que ce soit en Saôneet-Loire ou dans le Loiret, il est l'élu de la droite contre les républicains.

15. Il s'agit des sièges de l'Allier, de l'Hérault et de la Seine.

16. Valette, professeur de droit, est parfois considéré comme un républicain modéré. Ses votes à la Constituante le classent plutôt au centre droit. En juillet 1849, il est en outre l'élu de la droite contre le démocrate Ribeyrolles.

17. Le sortant, Ravez père, était un légitimiste, ancien président de la Chambre des députés sous la Restauration. Le parti de l'ordre proposait un orléaniste Gautier que les légitimistes refusèrent d'accepter, ils présentèrent donc le fils de Ravez ; voir les résultats ci-dessous.

18. Un ancien commissaire adjoint de 1848, Théophile Sylvestre, se présente contre le candidat démocrate-socialiste Aristide Pilhes (parent du représentant déchu) et ne se retire qu'une quinzaine de jours avant le scrutin.

19. Même observation de la part de Rouher à la Chambre: «Nous ne croyons pas [...] que la majorité du pays ait changé. Elle est toujours animée du même esprit d'ordre public qui a animé jusqu'à ce jour la majorité toute entière », Le Moniteur universel, 22 mars 1850, p. 957.

20. La Gazette des Tribunaux, 18-19 mars 1850.

21. La participation dépasse $70 \%$ en Ariège, en Charente, dans le Cher, le Loir-et-Cher, la Nièvre, les Hautes-Pyrénées, la Haute-Vienne. Les seules exceptions sont, pour des raisons facilement explicables, l'élection des Vosges (54,5\%) et le deuxième scrutin du Bas-Rhin (50,42\%), et plus surprenante, celle du Var (57,92\%).

22. Elles concernent les départements du Cher (deux sièges), de la Dordogne, du Finistère, des Landes, du Lot, du Morbihan, du Nord (deux scrutins), de la Seine-et-Mame, de la Seine et de la Haute-Vienne.

23. Philippe VICIER, La Seconde République dans la région alpine. Étude politique et sociale. Tome 2: Les paysans (1849-1852) Paris, Presses universitaires de France, 1963, 2 volumes, tome 2, pp. 274-275.

24. Pierre LÉVÊQUE, La Bourgogne de la Monarchie de Juillet au Second Empire, Lille, Atelier de reproduction des thèses, 1980, 5 volumes, tome 4, p. 1450.

25. Arch, nat., C 1330, Tableau des circonscriptions.

26. Georges DUPEUX, Aspects de l'histoire politique et sociale du Loir-et-Cher, 1848-1914, Paris, Imprimerie nationale, 1962, p. 362.

27. Le Moniteur universel, 24 mai 1851, pp. 1 467-1 468.

28. Le Moniteur universel, 26 mars 1850, p. 1001.

29. Le Moniteur universel, 6 avril 1850, pp. 1 110-1 111.

30. Le Moniteur universel, 27 mars 1850, pp. 1 012-1 014.

31. Pierre LÉVÊQUE, La Bourgogne..., ouv. cité, tome 4, p. 1450.

32. Le Moniteur universel, 5 août 1851, p. 2254.

33. Le Moniteur universel, 19 novembre 1850, p. 2385. 
34. Le Moniteur universel, 4 décembre 1850, p. 3451.

35. Le Moniteur universel, 16 novembre 1851, p. 2855.

36. Ainsi, dans trois cantons de Seine-et-Mame (Rozoy, Mormant et Lagny) en juillet 1851, on trouve dans les urnes des bulletins «terroristes": "Vils aristos, en 1852, lâches que vous êtes, nous vous pendrons et vous brûlerons tout vifs", "La guillotine est le plus profond républicain »; ou encore : «Vive la République, l'ordre et la guillotine ! », Le Moniteur universel, 17 juillet 1851, p. 2034.

37. Le Moniteur universel, juillet 1849, pp. 2375-2376 ; Le Siècle, 16 juillet 1849.

38. Arch, nat., C 1330 ; Le Moniteur universel, 20 juillet 1849, p. 2399 ; Élie REYNIER, La Seconde République dans l'Ardèche, Privas, Fédérations des œuvres laïques de l'Ardèche, 1998 (lère édition 1948), pp. 71-72.

39. Le Moniteur universel, 19 juillet 1849, p. 2391

40. Arch, nat., C 1330 ; Le Moniteur Universel, 18 juillet 1849, p. 2376.

41. Le Moniteur universel, $1^{\mathrm{er}}$ août 1849, p. 2547 ; Baron Eugène ESCHASSERIAUX, Mémoires d'un grand notable bonapartiste, présentés par François Pairault, Pons, Édition des Sires de Pons, 2000 , p. 24.

42. Idem.

43. Le Moniteur universel, 3 octobre 1849, p. 2956 ; Pierre LÉVÊQUE, La Bourgogne..., ouv. cité, tome 4, pp. 1 387-1 389.

44. Le Moniteur universel, 18 juillet 1849, p. 2375 ; Le Siècle, 18 juillet 1849.

45. Le Moniteur universel, 18 juillet 1849, p. 2376 ; Philippe VICIER, La Seconde République..., ouv. cité, tome 2, p. 228 ; Le Siècle, 14 et 17 juillet 1849.

46. Le Moniteur universel, 18 juillet 1849 ; Marcel DESSAL, La révolution de 1848 dans le département d'Eure-et-Loir, Chartres, 1948, p. 56.

47. Le Moniteur universel, 18 juillet 1849, p. 2378 ; J. DAGNAN, Le Gers sous la Seconde République : la réaction conservatrice (février 1842-2 décembre 1851), Auch, Imprimerie F. Cocharaux, 1928, p. 209; Le Siècle, 14 juillet 1849 .

48. Albert CHARLES, La Révolution de 1848 et la Seconde République à Bordeaux et dans le département de la Gironde, Bordeaux, Éditions Delmas, 1945, pp. 249-251; Le Moniteur universel, 20 octobre et 26 octobre 1849, p. 3353. Le nombre de votants est de 70390 plus 1728 votes comptabilisés ultérieurement.

49. Le Moniteur universel, 18 juillet 1849, p. 2378 ; Raymond HUARD, " Montagne rouge et Montagne blanche en Languedoc-Roussillon sous la Seconde République », dans Droite et Gauche de 1789 à nos jours. Actes du colloque de Montpellier, 9-10 juin 1973, Montpellier, Centre d'histoire contemporaine du Languedoc méditerranéen et du Roussillon, 1975, pp. 149-151.

50. Moins trois cantons, Olargues, Saint-Gervais, Bédarieux et les votes militaires.

51. Le Moniteur universel, 18 juillet 1849, p. 2375 ; Le Siècle, 14 juillet 1849.

52. Le Moniteur universel, 7 août 1849; p. 2604 ; Claude LATTA, Eugène Beaune (1799-1880): un républicain dans les combats du XIX ${ }^{e}$ siècle, Montbrison, C. Latta, 1995, p. 143.

53. Le Moniteur universel, 18 juillet 1849 ; Le Siècle, 14 juillet 1849.

54. Le Moniteur universel, 27 juillet 1849 ; Georges DUPEUX, Aspects de l'histoire politique..., ouv. cité, 1962, pp. 362-363.

55. Le Moniteur universel, 18 juillet 1849, p. 2376 ; Le Siècle, 16 et 18 juillet 1849.

56. Le Moniteur universel, 18 juillet 1849, p. 2377.

57. Le Moniteur universel, 18 juillet 1849, p. 2376 ; Le Siècle, 18 juillet 1849.

58. Le Moniteur universel, 20 juillet 1849, p. 2399 ; Le Siècle 13 juillet 1849.

59. Le Moniteur universel, 21 juillet 1849, p. 2415.

60. Le Moniteur universel, 18 juillet 1849, p. 2377 ; Pierre LÉVÊQUE, La Bourgogne..., ouv. cité, pp. 1384-1389.

Revue d'histoire du XIXe siècle, 22 | 2001 
61. Le Moniteur universel, 6 octobre 1849, p. 2980 ; Pierre LÉVÊQUE, La Bourgogne..., ouv. cité, pp. 1384-1389.

62. Le Moniteur universel, 14 juillet 1849, p. 2349.

63. Le Siècle, 17 octobre 1849 ; Le Moniteur universel, 20, 22, 26 octobre 1849, pp. 3217, 3260, 3350.

64. Adolphe ROBERT, Edgar BOURLOTON et Gaston COUGNY [dir.], Dictionnaire des parlementaires français, Paris, Bourloton, 1891, tome 1, p. 105 ; Le Siècle, 13 et 14 juillet 1849.

65. Le Siècle, 14 juillet 1849 ; Le Moniteur universel, 18 juillet 1849, p. 2376 ; Serge BIANCHI, «Le phénomène électoral dans le Sud de l'Ile de France sous la Seconde République », Revue d'histoire du XIX siècle, $\mathrm{n}^{\circ \circ} 16,1998$, p. 18.

66. Le Moniteur universel, 18 juillet 1849 ; p. 2576, Alain CORBIN, Archaïsme et modernité en Limousin aux XIX ${ }^{e}$ siècle (1845-1880), Paris, Marcel Rivière, 1975, p. 754.

67. Le Moniteur universel, 26 juillet 1849, p. 2472.

68. Le Moniteur universel, 20 octobre 1849, p. 3217 et 30 octobre 1849, p. 3416.

69. Le Moniteur universel, 23 mars 1850, p. 971.

70. Arch, nat., C 1330 ; Le Moniteur universel, 26 mars 1850, p. 1004, et 27 mars, p. 1012-1014 ; Élie REYNIER, La Seconde République dans l'Ardèche..., ouv. cité, p. 71.

71. Le Moniteur universel, 28 mars 1850 ; André ARMENGAUD, Les populations de l'Est aquitain au début de l'époque contemporaine (recherche sur une région moins développée, vers 1845-vers 1871), Paris, Imprimerie nationale, 1961, p. 384.

72. Le Moniteur universel, 13 février 1850, p. 512 ; Le Siècle, 11 février 1850 ; Arch, nat., C 1330.

73. Le Moniteur universel, 22 mars 1850.

74. Archives départementales du Gard, Lettre du préfet au ministre, 19 janvier 1850 ; Raymond HUARD, « Montagne rouge et Montagne blanche... », ouv. cité., pp. 151-160.

75. Le Moniteur universel, 26 mars 1850, Philippe VICIER, La Seconde République dans la région alpine..., ouv. cité, tome 2, pp. 274-275.

76. Le Moniteur universel, 26 mars 1850 ; Claude LATTA, Eugène Beaune..., ouv. cité, p. 143.

77. Le Moniteur universel, 22 mars 1850, p. 955 ; Auguste RIVET, La Vie politique dans le département de la Haute-Loire de 1815 à 1974, Le Puy, Éditions des Cahiers de la Haute-Loire, 1979, p. 73.

78. Le Moniteur universel, 20 mars 1850, p. 931 et 21 mars 1850, p. 946 ; Georges DUPEUX, Aspects de l'histoire politique..., ouv. cité, p. 366-371.

79. Le Moniteur universel, 21 mars 1850, p. 946 ; Charles-Ferdinand GAMBON, Dans les bagnes de Napoléon III : mémoires de Charles Ferdinand Gambon, publiées par Jean-Yves Mollier, Paris, Presses universitaires de France, 1983, p. 282.

80. Le Moniteur universel, 26 mars 1850, p. 1001.

81. Le Moniteur universel, 20 mars 1850 ; Arch, nat., C 1549.

82. Le Moniteur universel, 19 juin 1850, p. 2002.

83. Le Moniteur universel, 20 mars et 6 avril 1850 ; Gazette des Tribunaux, 18-19 mars 1850 ; Sylvie APRILE, Auguste Scheurer-Kestner (1833-1899) et son entourage : étude biographique et analyse politique d'une aristocratie républicaine, Thèse de doctorat, Université Paris 1, 1994, 3 volumes, f ${ }^{\circ} 123$.

84. Le Moniteur universel, 24 mars 1850 ; Pierre LÉVÊQUE, La Bourgogne..., ouv. cité, pp. 1448-1456.

85. Le Moniteur universel, 12 mai 1850, p. 1621.

86. Le Moniteur universel, 16 mars 1850, p. 885, 22 mars 1850, p. 955 ; Gazette des tribunaux, 16 mars 1850 ; Louis GIRARD, Nouvelle histoire de Paris. Tome 15 : La Deuxième République et le Second Empire, Paris, 1981, p. 65 et 76.

87. Le Moniteur universel, 8 mai 1850, p. 1557, Adolphe ROBERT, Edgar BOURLOTON et GASTON COUGNY [dir.], Dictionnaire des Parlementaires français..., ouv. cité, tome 5, pp. 347-48; Louis GIRARD, Nouvelle histoire de Paris..., ouv. cité, pp. 65 et 76.

88. Le Moniteur universel, 28 mars 1850, p. 1025-1026, et 3 mai 1850, p. 1483 ; Maurice AGULHON, Une ville ouvrière au temps du socialisme utopique: Toulon de 1815 à 1851, Paris/La Haye, Mouton, collection «Civilisations et Sociétés ", $\mathrm{n}^{\circ 0} 18,1977$, p. 309. 
89. Le Moniteur universel, 19 et 20 mars 1850 ; Alain CORBIN, Archaïsme et modernité en Limousin..., ouv. cité, pp. 755-757.

90. Le Moniteur universel, 4 avril 1850 ; Le Siècle, 24 mars 1850.

91. Arch, nat., C 1330 ; Le Moniteur universel, 4 décembre 1850.

92. Le Siècle, 16 juillet 1851 ; Le Moniteur universel, 10 juillet 1851, p. 2021.

93. Le Siècle, 27 et 30 septembre 1851; Journal des Débats, 30 septembre 1851; Le Moniteur universel, 7 novembre 1851, p. 2774.

94. Le Moniteur universel, 24 mai 1851, p. 1467 ; Le Siècle, 24 mai 1851.

95. Le Moniteur universel, 8 août 1851, p. 2298.

96. Le Moniteur universel, 7 novembre 1851, p. 2774.

97. Le Moniteur universel, 19 novembre 1850.

98. Le Moniteur universel, 5 août 1851, p. 2254 ; Alphonse-Marius GOSSEZ, Le département du Nord sous la Deuxième République 1848-1852 : étude économique et politique, Lille, G. Leleu, 1904, p. 371.

99. Le coup d'État de Louis-Napoléon empêcha la proclamation des résultats du vote. Notons que Devinck avait obtenu assez de voix pour être admis à la Chambre; Louis GIRARD, Nouvelle histoire de Paris..., ouv. cité, p. 66.

100. Le Moniteur universel, 17 juillet 1851, p. 2034 ; Le Siècle, 10 juillet 1851.

101. Le Moniteur universel, 20 juillet 1851; Le Siècle, 15 juillet 1851 ; Alain CORBIN, Archaïsme et modernité en Limousin..., ouv. cité, p. 757.

\section{RÉSUMÉS}

Les élections partielles à l'époque de l'Assemblée législative entre 1849 et 1851 n'ont jamais été étudiées dans leur ensemble. Elles sont un indicateur de l'évolution de l'opinion publique et mettent aussi en évidence quelques aspects méconnus de la pratique du suffrage pendant cette période.

Public opinion and the practice of suffrage from 1849 to 1851 . The by-elections for the Legislative Assembly between 1849 and 1851 have never been studied as a whole. They reveal the evolution of public opinion and political forces in the last years of the Second Republic and expose some new aspects of the practice of suffrage which announce the Second Empire.

\section{INDEX}

Mots-clés : Elections, Histoire politique, Opinion publique, Suffrage universel

\section{AUTEUR}

\section{RAYMOND HUARD}

Professeur émérite d'histoire contemporaine à l'Université Paul Valéry de Montpellier. 